УДК 628.349

\title{
Purification of Water \\ from the Copper, Zinc and Lead \\ by Sorbents from Inner Birch Bark
}

\author{
Evgeniya V. Veprikova, \\ Svetlana A. Kuznetsova* and Nikolay V. Chesnokov \\ Institute of Chemistry and Chemical Technology SB RAS \\ 50/24 Akademgorodok, Krasnoyarsk, 660036, Russia
}

Received 18.03.2015, received in revised form 20.04.2015, accepted 16.05.2015

Processes of the copper, zinc and lead ions sorption from water solutions by sorbents from inner birch bark were studied. It was established, that the obtained sorbents absorb the metal ions in a wide range of concentrations. The $\mathrm{pH}$ values corresponding the highest sorption of metal ions were determined. It was shown that the sorbents from inner birch bark have the high performance in purification of the diluted wastewater.

Keyword: sorbent from inner birch bark, sorption, copper, zinc, lead.

DOI: $10.17516 / 1998-2836-2015-8-2-202-210$.

(c) Siberian Federal University. All rights reserved

* Corresponding author E-mail address: inm@icct.ru 


\title{
Очистка воды от меди, цинка и свинца сорбентами из луба коры березы
}

\author{
Е.В. Веприкова, С.А. Кузнецова, Н.В. Чесноков \\ Институт химии и химической технологии СО РАН \\ Россия, 660036, Красноярск, Академгородок, 50/24
}

Изучены процессы сорбиии ионов меди, ијинка и свинца из водных растворов сорбентами из луба коры березы. Установлено, что полученные сорбенты поглощают ионы металлов в широком диапазоне концентраций. Определены значения рН растворов, при которых достигается наибольшая сорбиия ионов исследуемых металлов. Показано, что применение сорбентов из луба наиболее эффективно для очистки от ионов металлов разбавленных водных стоков.

Ключевые слова: сорбент из луба коры березы, сорбция, медь, иинк, свинец.

\section{Введение}

Задача очистки природных и сточных вод от токсичных, в том числе тяжелых, металлов эффективно решается при использовании различных углеродных сорбентов. Сырьевые источники для получения таких материалов весьма многообразны. Особую группу составляют отходы переработки биомассы. Активные пористые материалы из растительных отходов имеют значительный практический интерес для решения ряда экологических задач промышленно насыщенных регионов: очистки сточных вод, газовых выбросов, грунта и др. Известно, что такие сорбенты способны извлекать тяжелые металлы из водных стоков, тем самым снижая антропогенную нагрузку на объекты гидросферы [1-5].

Применение сорбентов из отходов биомассы экономически оправдано для небольших производств, приближенных к источникам доступного сырья. Анализ структуры сырьевой базы отходов растительного происхождения в России показывает, что наиболее перспективными по своей доступности и масштабности для получения сорбционных материалов являются отходы деревоперерабатывающей промышленности. Важно отметить в этом отношении многотоннажные отходы коры, которые в основном вывозятся в отвалы или сжигаются. Так, плановый объем отходов коры березы на Енисейской фанерной фабрике составляет 25-30 тыс. м³ в год. Промышленное использование коры березы ограничивается производством дегтя и декоративных изделий из бересты. Следует отметить, что из луба и коры березы можно получать пористые материалы различного назначения [6, 7].

Цель работы - изучение сорбции меди, цинка и свинца из водных растворов сорбентами из луба коры березы.

\section{Экспериментальная часть}

В качестве сырья для получения сорбентов использовали воздушно-сухую (влажность $7,5 \pm 0,5 \%$ кору березы повислой Betula pendula Roth., отобранную из отходов окорки на Крас-

$$
-203-
$$


ноярском деревообрабатывающем комбинате. Кору измельчали на дезинтеграторе марки «8255 Nossen» (Германия). В процессе измельчения достигалось одновременное разделение на луб и бересту за счет их различной механической прочности. Использованная техника измельчения позволила получить лубяной продукт (луб) с размером частиц менее 0,5 мм и содержанием бересты $(15,8 \pm 0,5) \%$. Луб имел следующий состав (\% от массы абсолютно сухого вещества): содержание трудно- и легкогидролизируемых полисахаридов - 48,8 \%; лигнина - 33,1 \%; водорастворимых веществ - 13,7 \%; золы - 2,4 \%.

Луб служил сырьем для получения сорбента СКБ-1. Для получения сорбента СКБ-2 использовали твердый остаток последовательной экстракции луба различными растворителями - гексаном, этилацетатом, изопропанолом и водой.

Анализ состава сырья и экстракцию луба органическими растворителями проводили по общепринятым в химии древесины методикам.

Сорбенты получали обработкой луба и ТОЭ 2\%-ным водным раствором $\mathrm{NaOH}$ при следующих условиях: температура обработки $(65 \pm 5)^{\circ} \mathrm{C}$; время обработки 1 ч, значение гидромодуля 5, при перемешивании по методике [8]. Образцы сушили при $(100 \pm 5){ }^{\circ} \mathrm{C}$ и измельчали до размера менее 250 мкм.

Образец БАУ ох используемый как образец сравнения, был приготовлен обработкой активного угля БАУ (ГОСТ 6217-74) $25 \% \mathrm{HNO}_{3}$ по методике работы [9].

Изотермы сорбции были получены с применением модельных растворов сульфата меди, хлорида цинка и нитрата свинца различных концентраций при $\mathrm{pH}$ 5,0. Концентрацию растворов варьировали в интервале $0,001-0,850$ г/л для $\mathrm{Cu}^{2+} ; 001-0,950$ г/л для $\mathrm{Zn}^{2+}$ и $0,001-2,101$ $\Gamma / л$ для $\mathrm{Pb}^{2+}$. Сорбцию проводили в статических условиях при встряхивании навески сорбента $\left(0,1\right.$ г) с модельным раствором (100 мл) при температуре $(20 \pm 1){ }^{\circ} \mathrm{C}$ в течение 24 ч. В остальных экспериментах продолжительность сорбции составляла 1 ч.

Значения $\mathrm{pH}$ модельных растворов, содержащих $\mathrm{Zn}^{2+}$ и $\mathrm{Pb}^{2+}$, варьировали от 3,0 до 6,5, а для раствора $\mathrm{Cu}^{2+}$ - от 3,0 до 5,5. Концентрация ионов металлов в модельных растворах составляла 0,65 г/л.

Десорбцию ионов металлов с поверхности сорбентов проводили дистиллированной водой при $(20 \pm 1){ }^{\circ} \mathrm{C}$ в течение 24 ч. Соотношение сорбента и воды составляло 0,1 г к 100 мл.

Изменение концентрации $\mathrm{Cu}^{2+}, \mathrm{Zn}^{2+}$ и $\mathrm{Pb}^{2+}$ в модельных растворах в процессе сорбции и десорбции определяли фотометрическими методами согласно методикам ГОСТ 18293 - 72 . Точность определения контролировали атомно-абсорбционным методом на приборе Analyst-400. Все представленные в работе результаты являются усредненным значением трех измерений. Ошибка определения не превышала $5 \%$.

По изменению концентрации исследуемых металлов в растворе рассчитывали величину сорбционной емкости сорбентов (А, мг/г) и степень очистки (L, \%) растворов.

Значение предельной сорбционной емкости $\mathrm{A}_{\infty}$ сорбентов по цинку определяли графически на основании изотермы. Значение $\mathrm{A}_{\infty}$ по меди рассчитывали согласно уравнению изотермы сорбции Ленгмюра:

$$
\mathrm{A}^{-1}=\left(\mathrm{A}_{\infty} \mathrm{K}_{\mathrm{L}}\right)^{-1} \mathrm{C}_{\mathrm{p}}^{-1}+\mathrm{A}_{\infty}^{-1} \text {, }
$$


где $\mathrm{A}$ - сорбционная емкость, мг/г; $\mathrm{A}_{\infty}$ - предельная сорбционная емкость, мг/г; $\mathrm{C}_{\mathrm{p}}-$ равновесная концентрация $\mathrm{Cu}^{2+}$, мг/л; $\mathrm{K}_{\mathrm{L}}$ - константа уравнения Ленгмюра.

\section{Результаты и обсуждение}

Установлено, что сорбенты из луба березы СКБ-1 и твердого остатка его экстракции СКБ-2 по способности поглощать медь, цинк и свинец из водных модельных растворов различаются незначительно (табл. 1).

Данные табл. 1 показывают, что сорбционная емкость сорбентов в отношении свинца существенно выше, чем по цинку и меди. Следует отметить, что в случае сорбции $\mathrm{Pb}^{2+}$ в исследованном интервале концентраций предельная сорбционная емкость не была достигнута и в табл. 1 приводятся максимальные значения $\mathrm{A}_{\mathrm{Pb}}^{2+}$.

Известно, что в ряду $\mathrm{Zn}^{2+}-\mathrm{Cu}^{2+}-\mathrm{Pb}^{2+}$ значения ковалентных индексов $\mathrm{X}_{\mathrm{m}}^{2} \mathrm{r}\left(\mathrm{X}_{\mathrm{m}}\right.$ электроотрицательность иона металла, $\mathrm{r}$ - ионный радиус, соответствующий наиболее часто встречающемуся координационному числу) увеличиваются и составляют 2,16 - 2,97 - 3,28 соответственно [10]. Ковалентный индекс принято считать мерой вовлечения ионов в ковалентное взаимодействие с поверхностью сорбента [11]. Наблюдаемое изменение $\mathrm{X}_{\mathrm{m}}{ }^{2} \mathrm{r}$ коррелирует с увеличением сорбции ионов металлов в приведенном ряду (табл. 1). Для $\mathrm{Pb}^{2+}$ наблюдается сочетание наибольшего значения $\mathrm{X}_{\mathrm{m}}^{2} \mathrm{r}$ с высокими значениями его сорбции. Очевидно, образование ковалентных связей ионов свинца с функциональными группами сорбентов вносит больший вклад в его сорбцию по сравнению с $\mathrm{Zn}^{2+}$ и $\mathrm{Cu}^{2+}$.

На примере сорбента СКБ-1 показано, что характер сорбции $\mathrm{Pb}^{2+}$ из модельного раствора существенно отличается от сорбции $\mathrm{Cu}^{2+}$ и $\mathrm{Zn}^{2+}$ (рис. 1 и 2).

Процессы поглощения $\mathrm{Cu}^{2+}$ и $\mathrm{Zn}^{2+}$ из модельных растворов описываются ленгмюровскими изотермами I типа по классификации БЭТ, что свидетельствует о монослойной сорбции этих ионов (рис. 1) [11].

Сорбция свинца имеет более сложный характер (рис. 2). В области низких концентраций (до 0,51 г/л) достигается насыщение, очевидно, из-за заполнения монослоя. Дальнейшее увеличение равновесной концентрации $\mathrm{Pb}^{2+}$ в растворе сопровождается ростом значений сорбции. Возможно, это обусловлено многослойной сорбцией ионов свинца с образованием полиядерных комплексов $[10,11]$. Полученная изотерма относится к типу II по классификации БЭТ.

Установлено, что сорбция исследуемых металлов по-разному зависит от изменения рН модельных растворов (рис. 3, начальная концентрация ионов металлов в модельных растворах составляла 0,65 г/л).

Таблица 1. Сорбционная емкость сорбентов из луба березы (СКБ-1) и твердого остатка экстракции (СКБ-2) в отношении меди, цинка и свинца

\begin{tabular}{|l|l|l|l|}
\hline \multirow{2}{*}{ Образцы сорбентов } & \multicolumn{3}{|c|}{ Сорбционная емкость, мГ/Г * } \\
\cline { 2 - 4 } & \multicolumn{1}{|c|}{$\mathrm{A}_{\infty \mathrm{Cu}}{ }^{2+}$} & \multicolumn{1}{|c|}{$\mathrm{A}_{\propto \mathrm{Zn}}{ }^{2+}$} & $\mathrm{A}_{\mathrm{Pb}}{ }^{2+}$ \\
\hline СКБ-1 & $12,2 \pm 0,2$ & $11,7 \pm 0,3$ & $136,6 \pm 4,1$ \\
\hline СКБ-2 & $12,0 \pm 0,2$ & $11,3 \pm 0,3$ & $134,5 \pm 4,1$ \\
\hline
\end{tabular}

Примечание. Значения сорбционной емкости получены при рН 5,0; $\mathrm{A}_{\infty}$ - предельная сорбционная емкость.

$$
-205-
$$




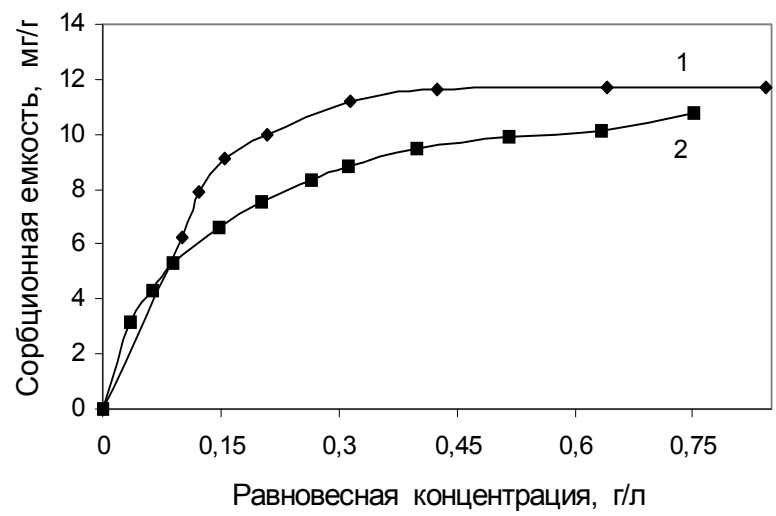

Рис. 1. Изотермы сорбции $\mathrm{Zn}^{2+}(1)$ и $\mathrm{Cu}^{2+}$ (2) сорбентом СКБ-1 при $\mathrm{pH}$ 5,0

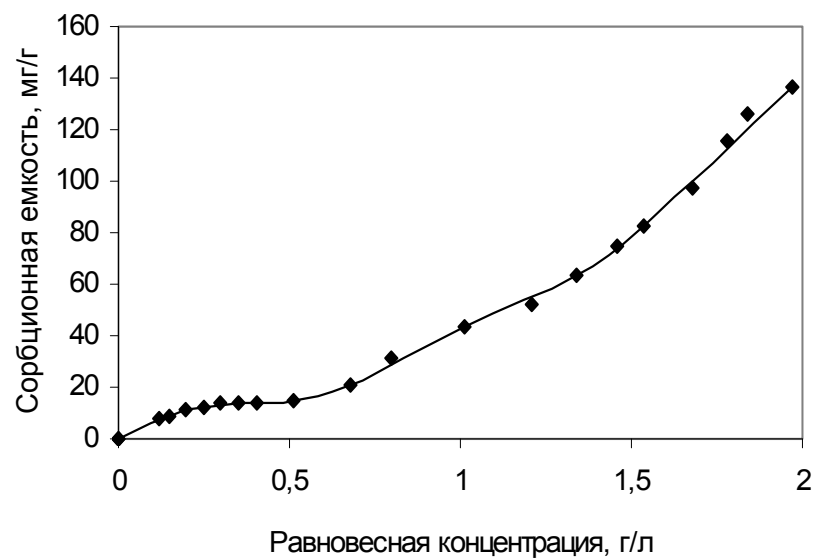

Рис. 2. Изотерма сорбции $\mathrm{Pb}^{2+}$ сорбентом СКБ-1 при $\mathrm{pH}$ 5,0

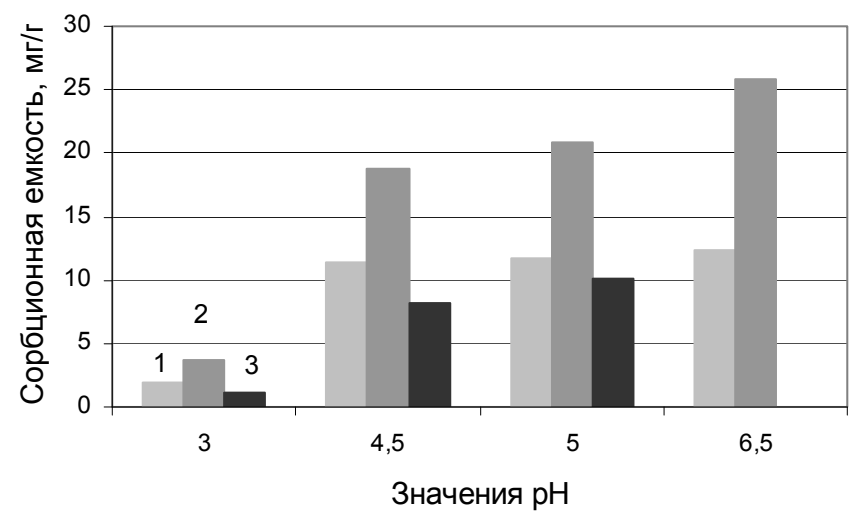

Рис. 3. Зависимость сорбции $\mathrm{Zn}^{2+}(1), \mathrm{Pb}^{2+}(2)$ и $\mathrm{Cu}^{2+}$ (3) сорбентом СКБ-1 от $\mathrm{pH}$ модельных растворов 
Понижение кислотности в исследованном интервале приводит к существенному увеличению сорбции ионов меди и свинца. Это можно объяснить вовлечением во взаимодействие с ионами металлов слабокислотных функциональных групп сорбентов [4]. В отличие от них сорбция ионов цинка изменяется очень мало при изменении $\mathrm{pH}$ модельного раствора от 4,5 до 6,5 .

Было установлено, что сорбент СКБ-2 по своей сорбционной емкости в отношении исследуемых металлов при различных значениях рН растворов мало отличается от сорбента СКБ-1. Зафиксированное максимальное различие значений сорбции не превышало $\pm 1,5$ мг/г.

Следует отметить, что для меди понижение кислотности возможно только до $\mathrm{pH}$ 5,5. Выше этого значения $\mathrm{pH}$ растворы теряют стабильность из-за выпадения осадка, что приводит к искажению результатов по определению сорбционной емкости. В случае цинка и свинца повышение $\mathrm{pH}$ модельных растворов возможно только до 6,5 \pm 0,2 также из-за выпадения осадка гидроокисей металлов.

Значения сорбционной емкости сорбента из луба при $\mathrm{pH}$ 3,0 крайне малы для всех металлов (рис. 3). Поэтому применять их для очистки кислых сточных вод нецелесообразно. Для эффективного удаления цинка и свинца из стоков можно рекомендовать интервал $\mathrm{pH} 4,5-6,5$, а для меди - pН 5,0 - 5,5.

Были проведены эксперименты по определению десорбции ионов металлов с поверхности сорбентов СКБ-1 и СКБ-2. При использовании выбранных методов контроля с чувствительностью 5 мкг/дм ${ }^{3}$ изменений концентрации ионов меди, цинка и свинца в растворе не установлено. Отсутствие десорбции можно объяснить образованием прочных комплексов ионов металлов с кислородсодержащими, прежде всего карбоксильными, группами сорбентов из луба.

Известно, что применение сорбентов растительной природы наиболее эффективно для очистки низкоконцентрированных растворов, содержащих токсичные металлы. Растворы с концентрацией металлов 1,0 - 10,5 мг/л моделируют воду с границей, превышающей допустимую концентрацию токсичных металлов и сточные воды некоторых технологических процессов - промывные воды переработки металлсодержащего вторичного сырья, промывные воды гальванопроизводств и др. [12].

На рис. 4 приведены результаты сорбции меди сорбентом СКБ-2 (расход сорбента 4 г/л, pH 5,0).

Наиболее эффективное удаление $\mathrm{Cu}^{2+}$ происходит из растворов с начальной концентрацией металла менее 10,5 мг/л - степень очистки составляет более 63,5 \%. По сорбции меди сорбент из луба существенно уступает только окисленному образцу БАУ ох, вероятно, из-за меньшего содержания функциональных групп на его поверхности. Сравнение степеней очистки модельных растворов от меди сорбентом из луба СКБ-2 и БАУ выявило, что в интервале концентраций 5,0 - 52,7 мг/л данный показатель для СКБ-2 ниже значений для БАУ на 9,2 - 16,7 \% (рис. 4). Это позволяет считать сорбент из луба перспективным материалом для очистки водных стоков от примесей токсичных металлов.

Было установлено, что по степени очистки низкоконцентрированных модельных растворов сорбентом СКБ-2 ионы металлов можно расположить в следующий ряд: $\mathrm{Pb}^{2+}>\mathrm{Cu}^{2+}>\mathrm{Zn}^{2+}$ (табл. 2).

$$
-207-
$$




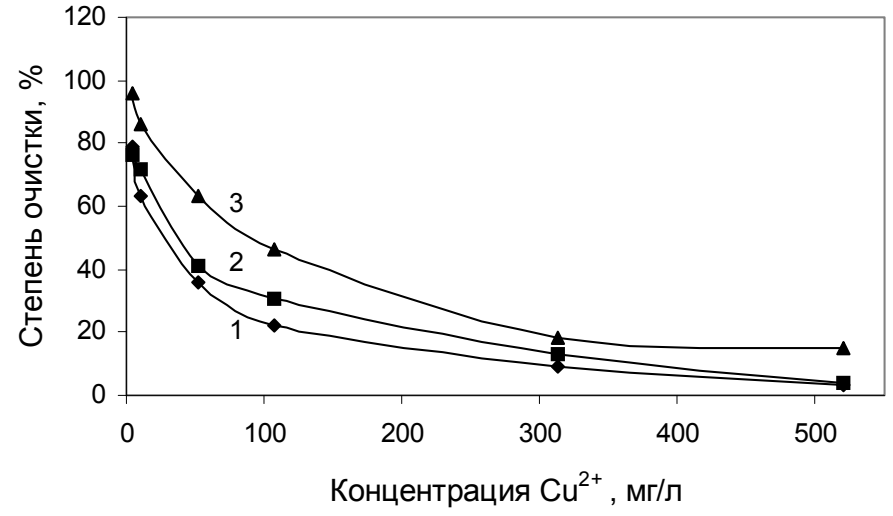

Рис. 4 Степень очистки водных растворов от $\mathrm{Cu}^{2+}$ в зависимости от исходной концентрации металла (pH 5,0): 1 - сорбент СКБ-2; 2 - БАУ; 3 - БАУ

Таблица 2. Результаты очистки низко концентрированных модельных растворов от свинца, меди и цинка при рН 5,0

\begin{tabular}{|c|c|c|}
\hline \multirow{2}{*}{ Металл } & Степень очистки при различной начальной концентрации $\left(\mathrm{C}_{\mathrm{o}}\right)$ растворов, \% \\
\cline { 2 - 3 } & $\mathrm{C}_{\mathrm{o}} 10,5$ мг/л & $\mathrm{C}_{\mathrm{o}} 1,0$ мг/л \\
\hline $\mathrm{Pb}^{2+}$ & 65,4 & $86,3(86,6)^{*}$ \\
\hline $\mathrm{Cu}^{2+}$ & 63,5 & $79,9(80,4)^{*}$ \\
\hline $\mathrm{Zn}^{2}$ & 50,1 & $64,2(63,8)^{*}$ \\
\hline
\end{tabular}

Примечание. *В скобках приведены данные для БАУ

Видно, что исследованный сорбент наиболее эффективен для очистки модельных растворов, содержащих 1,0 мг/л свинца и меди. Причем в этом случае он по способности удалять металлы практически не уступает БАУ ох. Это позволяет рекомендовать сорбенты из луба коры березы для доочистки воды технического назначения от примесей свинца и меди.

\section{Заключение}

Исследованы сорбционные свойства сорбентов из луба березы в отношение ионов меди, цинка и свинца в широком диапазоне концентраций и различных значений $\mathrm{pH}$ модельных растворов. Установлено, что сорбенты, полученные из луба и твердого остатка его экстракции, схожи по сорбционной активности в отношении исследованных металлов. Эти сорбенты характеризуются большей сорбционной активностью в отношении свинца. Показано, что сорбенты из луба коры березы наиболее эффективны для очистки водных стоков с концентрацией металлов менее 10,5 мг/л.

\section{Список литературы}

1. Неманова Ю.В., Стокозенко И.Г., Титова Ю.В. Оценка возможности использования растительного сырья в качестве сорбентов компонентов сточных вод // Химия растительного сырья. 2012. № 2, С. 47 - 50. [Nemanova Y.V., Stokozenko I.G., Titova Y.V. Estimation of ability of

$$
-208-
$$


plant raw materials using as sorbents of wastewater components. Chemistry of Plant Raw Materials. 2012. N. 2, P. 47 - 50. (in Russ.)]

2. Фогель А.А., Сомин В.А., Комарова Л.Ф. Изучение сорбционных материалов на основе отходов производства древесины и минерального сырья // Химия в интересах устойчивого развития. 2011. T. 19 (4), C. 461 - 465.[ Fogel A.A., Somin V.A., Komarova L.F. Investigation of the sorption properties of materials based on wastes from wood production and mineral raw materials. Chemistry for Sustainable Development. 2011. V.19 (4), P. 461 - 465. (in Russ.)]

3. Nuang L.Y., Ou Z.Y., Boving T.B., Tyson J., Xing B.S. Sorption of copper by chemically modified aspen wood fibers // Chemosphere. 2009. V.76 (8), P. 1056 - 1061.

4. El-Hendawy A.N.A. The role of surface chemistry and solution $\mathrm{pH}$ on removal of $\mathrm{Pb}^{2+}$ and $\mathrm{Cd}^{2+}$ ions via effective adsorbents from low cost biomass // J. Hazard. Mater. 2009. V.167 (1-3), P. $260-267$.

5. El-Shafey E.I. Removal of $\mathrm{Zn}(\mathrm{II})$ and $\mathrm{Hg}$ (II) from aqueous solution on a carbonaceous sorbent chemically prepared from rice husk // J. Hazard. Mater. 2010. V.175 (1-3), P. 319 - 327.

6. Веприкова Е.В., Кузнецова С.А., Чесноков Н.В., Кузнецов Б.Н. Свойства энтеросорбентов, полученных иммобилизацией фурацилина и желатина на пористой подложке из луба коры березы. Журнал Сибирского федерального университета. Химия. 2014. Т. 7 (1), C. 100 - 111. [Veprikova E.V., Kuznetsova S.A., Chesnokov N.V., Kuznetsov B.N. Properties of enterosorbents obtained by immobilization of furacilin and gelatin on the porous carrier from inner birch bark. Journal of Suberian Federal University. Chemistry. 2014. V. 7 (1), P. 100 - 111. (in Russ.)]

7. Кузнецова С.А., Кузнецов Б.Н., Скурыдина Е.С., Максимов Н.Г., Калачева Г.С., Ульянова О.А., Скворцова Г.П. Синтез и свойства биокомпозитных удобрений на основе мочевины и коры березы. Журнал сибирского федерального университета. Химия. 2013. Т. 6 (4). С. 380 - 393. [ Kuznetsova S.A., Kuznetsov B.N., Skurydina E.S., Maksimov N.G., Kalachova G.S, Ulyanova O.A., Skvortsova C.P. Synthesis and properties of biocomposite fertilizers on the basis of urea and birch bark. Journal of Suberian Federal University. Chemistry. 2013. V. 6 (4), P. 380 - 393. (in Russ.)]

8. Патент 2311954 РФ. Кузнецова С.А., Кузнецов Б.Н., Ковальчук Н.М., Скворцова Г.П. Энтеросорбент. Опубл. 20.05.2010. [Patent 2389498 RU. Kuznetsova S.A.,Shchipko M.L., Kuznetsov B.N., Koval'chuk N.M., Veprikova E.V., Lezova A.A. Enterosorbent and a method for preparation thereof. Publ. Date 10.12.2007 (in Russ.)]

9. Ставицкая С.С., Картель Н.Т., Викарчук В.М., Петренко Т.П., Цыба Н.Н., Зайцев Ю.П., Баклинская О.Н., Стрелко В.В. Новые микропористые углеродные сорбенты из технического лигнина // Экотехнологии и ресурсосбережение. 2005. № 6, С. 42 - 48. [Stavitskaya S.S., Kartel N.T., Vikarchuk V.M., Petrenko T.P., Tzyba N.N., Zaitsev Yu.P., Bakalinskaya O.N., Strelko V.V. New microcellular carbon sorbents from technical lignin. J. Ecotechnologii and Resource-saving. 2005. N.6, P. 42 - 48. (in Russ.)]

10. Хохотва А.П. Адсорбция тяжелых металлов сорбентом на основе сосновой коры // Xuмия и технология воды. 2010. Т.32 (6), С. 604 - 612.[Khokhotva O.P. Sorption of heavy metals on a sorbent based on pine bark. J. of Water Chemistry and Technology. 2010. V.32 (6), P. 604 - 612. (in Russ.)] 
11. Адсорбция из растворов на поверхности твердых тел: пер. с англ. / под ред. Г. Парфита, Л. РочестераМ.: Мир, 1986. 488 с. [Adsorption from Solution at the Solid Liquid Interface. Edited by G. Parfit, C. Rochester.: transl. from eng. Moscow: World, 1986.488p. (in Russ.)]

12. Багровская Н.А., Никифорова Т.Е., Козлов В.А., Лилин С.А. Сорбционные свойства модифицированных древесных опилок // Химия в интересах устойчивого развития. 2006. Т. 14 (1). C. 1-7. [Bagrovskaya N.A., Nikiforova T.E., Kozlov V.A., Lilin S.A. Sorption properties of modified wood chips. Chemistry for Sustainable Development. 2006.V.14 (1). P. 1 - 7. (in Russ.)] 